\title{
Kontribusi Peran Orangtua dan Guru dalam Pembentukan Karakter Islami Anak Usia Dini
}

\author{
Ida Windi Wahyuni*, Ary Antony Putra \\ Universitas Islam Riau, Indonesia \\ Jl. Kaharuddin Nst No.113, Simpang Tiga, Kec. Bukit Raya, Kota Pekanbaru, Riau 28284 \\ Email: idawindi@fis.uir.ac.id
}

\begin{abstract}
PAUD Sekato is a PAUD institution with a general curriculum, but the majority of the area's population is Muslim, Islamic education material is only given in general material to support students' simple understanding. The aim to be achieved is to determine the contribution of the role of parents and teachers in the formation of Islamic character and influencing factors. This research is descriptive qualitative research. Research subjects are parents, teachers, and school principals of PAUD Sekato, Mandiangin Village, Minas District, Siak Regency. This research uses descriptive qualitative research methods. This study presents the results of in-depth interviews, observations, and documentation to make conclusions. The results showed that the contribution of the role of parents and teachers in the formation of the Islamic character of PAUD Sekato students by teaching them to apply character values based on Islam, and monitoring student development, (2) Factors influencing him were parental support, discipline, teacher professionalism, exemplary news, and sosial media. While the inhibiting factor, is the mass media, the parenting program has not been implemented, there are some students whose environment does not reflect Islamic character.
\end{abstract}

Keywords: Parents, Teachers, Islamic Characters

Abstrak: PAUD Sekato merupakan lembaga PAUD dengan kurikulum umum, namun lingkungan daerah tersebut penduduknya mayoritas beragama Islam, materi pendidikan agama Islam hanya diberikan dalam materi umum untuk menunjang pemahaman siswa secara sederhana. Tujuan penelitian adalah untuk mengetahui kontribusi peran orang tua dan guru dalam pembentukan karakter Islami serta faktorfaktor yang mempengaruhinya. Penelitian ini menggunakan metode penelitian deskripstif kualitatif. Subyek penelitian yaitu orang tua, guru dan kepala sekolah PAUD Sekato Desa Mandiangin, Kecamatan Minas Kabupaten Siak. Penelitian ini memaparkan hasil wawancara, observasi dan dokumentasi yang mendalam untuk dibuat kesimpulan. Hasil penelitian menunjukkan bahwa kontribusi peran orang tua dan guru dalam pembentukan karakter Islami siswa PAUD Sekato dengan mengajarkan menerapkan nilai-nilai karakter yang berlandaskan Islam, dan memantau perkembangan siswa, (2) Faktor yang mempengaruhinya adalah dukungan orang tua, kedisiplinan, profesionalisme guru, keteladanan, dan media sosial. Sedangkan faktor penghambatnya, adalah media massa, belum terselenggaranya program parenting, ada sebagian siswa yang lingkungannya tidak menceriminkan karakter Islami.

Kata Kunci: Orang Tua, Guru, Karakter Islami

Jurnal Pendidikan Agama Islam Al-Thariqah Vol. 5, No. 1, Januari - Juni 2020

Received: 19 April 2020; Accepted 19 June 2020; Published 25 June 2020

*Corresponding Author: idawindi@fis.uir.ac.id 


\section{PENDAHULUAN}

Membangun karakter pada seseorang merupakan dasar terbentuk sikap, nilai dan kedewasaan dengan didukung oleh orang ada di sekitarnya sejak lahir, dengan siapa anak bergaul, pengajar dan pemerintah tempat tinggalnya. Kemampuan yang dimiliki anak baik yang berasal dari aspek pengetahuan, perasaan, dan fisik motoriknya dapat menjadi akar terbentuknya karakter dalam diri anak itu sendiri.

Keluarga merupakan wadah pembentukan karakter anak. Sebuah keluarga, orang tua menjadi model pengembangan dan terbentuknya karakter anak (La Fua, 2018: 1). Memasuki usia sekolah, maka guru sebagai penggerak dan penerus karakter yang telah dibentuk dalam keluarganya. Memiliki adab, etika dan kebiasaan yang baik dalam berbagai kegiatan yang telah diprogram oleh sekolah.

Sebagaimana diungkapkan dalam penelitian yang telah dilakukan oleh Prasanti dan Fitriani (2018: 19), yakni keluarga, sekolah dan lingkungan di luar (bermain, les, dan pengembangan bakat) mempengaruhi pembentukan karakter anak.

Islam adalah agama sempurna, segala perilaku manusia dari yang sangat kecil diatur dan dijelaskan dalam AlQur'an. Nabi Muhammad SAW menjadi teladan bagi umat Islam dalam berperilaku sehari-hari. Pendidikan karakter telah ada dan diajarkan sejak zaman Nabi Muhammad SAW, sehingga umat Islam dianjurkan untuk mengikuti segala perilaku yang telah dicontohkan oleh Nabi-nabi terdahulu.

Penjelasan tentang sifat dan kemampuan manusia memiliki pengelihatan, pendengaran dan nurani untuk dilatih dan dibina sehingga tidak terpengaruh oleh penyimpangan yang tidak diatur dalam Al-Qur'an (Q.S. AnNahl: 78). Agama Islam mengajarkan agar selalu berpedoman pada karakter Nabi Muhammad SAW (Rizkia dan Zaedi, 2019: 23). Pendidikan, perasaan, maupun perilaku yang positif menjadi dasar dalam pendidikan karakter. Selain itu, perlu dikembangkan juga rasa peduli, jujur, adil, bertanggungjawab, saling menghormati, tekun, etos kerja tinggi, dan gigih (Ismail, 2012).

Pembentukan kematangan dan kemandirian pribadi seseorang berawal dari pengembangan sikap, moral, agama, sosial emosionalnya (Wahyuni, 2018: 52). Usia dini adalah waktu yang tepat untuk memulai pembentukan karakter Islami, karena usia dini sebagai pondasi membentuk kepribadian yang tangguh serta memiliki konsep yang tepat dan tidak terpengaruh pada lingkungan negatif. Dasar pembentukan karakter dimulai dari usia dini (Kusumandari, 2013: 20).

Sriwahyuni (2015: viii) dalam penelitiannya mengungkapkan bahwa mengembangkan karakter keagamaan, disiplin, toleransi, santun dan demokratis. Pendidikan Pondok Pesantren API Darussalam Pulungan membentuk anak menjadi santri yang religius, jujur, peduli, mandiri, toleransi dan sopan.

Sementara itu, Ulya (2015: iv) melakukan penelitian dengan melibatkan siswa sekolah menyimpulkan hasil risetnya bahwa nilai karakter Islami yang diterapkan dengan metode hapalan takhasus dapat membentuk nilai kejujuran, rajin, bekerja keras, bertanggung jawab, berminat pada literasi memiliki disiplin tinggi.

Satriani (2017: xi) mengungkapkan bahwa adanya kerjasama antara guru dan orang tua dengan aktif dalam setiap pertemuan yang diadakan oleh sekolah, membina anak yang sesuai dengan pendidikan Islam, penanaman tauhid, mengadakan program outing class, terbiasa sholat dhuha, silaturrahmi pada keluarga siswa, mengaktifkan buku komunikasi, menjadi contoh kebiasaan- 
kebiasaan yang positif untuk kegiatan sehari-hari. Usaha ini sangat efektif sehingga membentuk santri yang lebih dewasa dan bertanggungjawab sebagai upaya untuk membentuk karakter Islami siswa SDIT Wahdah Islamiyah.

PAUD Sekato terletak di Kecamatan Minas Kabupaten Siak, berdiri tahun 2009. Awal didirikan sekolah hanya memiliki 35 siswa yang terbagi dalam dua kelompok belajar. Tenaga pendidik terdiri dari kepala sekolah dan 2 pengajar. Kurikulum umum yang diterap pada PAUD ini tetap berpegang teguh pada landasan Islam yang didukung oleh lingkungan yang mayoritas beragama Islam. Penelitian ini dilakukan untuk menguraikan kontribusi peran orang tua dan guru dalam pembentukan karakter Islami siswa.

Berdasarkan dari permasalahanpermasalahan yang disebutkan di atas, maka rumusan masalah yang diajukan adalah sejauhmana kontribusi peran orang tua dan guru dalam pembentukan karakter Islami siswa? dan dipengaruhi oleh faktor apa dalam pembentukan karakter islami siswa?

Adapun tujuan penelitiannya adalah untuk mengetahui kontribusi peran orangtua dan guru dalam pembentukan karakter Islami siswa PAUD Sekato serta faktor-faktor yang mempengaruhinya.

\section{KONSEP TEORI}

\section{Pembentukan Karakter Islami}

Pembentukan karakter Islami merupakan suatu identitas yang tampak pada perilaku seseorang secara yang dinamis berlandaskan norma-norma Islam dengan penjelasan yang lengkap pada sumber ajaran Islam. Peranan penting pendidikan dalam mencetak generasi selanjutnya.

Salah satu tempat terbaik dalam pembentukan dan pengembangan karakter anak berada di lingkungan sekolah. Pendidikan karakter bagian dari penanaman akhlak yang baik, yakni pengetahuan yang memberikan pengajran, pembinaan, bimbingan dan pelatihan kepada peserta didik agar memiliki akhlak yang baik dan Islami merupakan bagian dari pengembangan ilmu dalam membina mental keberagamaan dan perilaku seseorang (Salim, 2013).

Sikap-sikap yang baik, positif, berwawasan yang luas, cerdas, dan aktif dengan pergaulan tempat tinggalnya sehingga terbentuk sesuatu yang harmoni merupkan bagian dari manfaat Pendidikan karakter (Ismail, 2012). Lingkungan tempat tinggal dimana anak itu berada menjadi awal terbentuknya karakter, termasuk tahapan yang diawali dari kelahiran hingga lima tahun usianya.

Adapun cara yang tepat dalam membentuk karakter Islami pada anak adalah membiasakan dan memberikan contoh perilaku-perilaku yang baik serta penanaman akhlak sejak usia dini. Pendidikan karakter untuk menuju terbentuknya perilaku yang baik pada siswa dengan tiga kemampuan yang harus dimilikinya, yakni pengetahuan, sikap dan keterampilan. Begitu pun dengan guru harus memiliki kemampuan tersebut (Majid, dan Dian Andayani, 2012).

Indikator-indikator karakter harus diimplementasikan pada kurikulum sekolah, antara lain: (Najib, dkk, 2016) menjaga harga diri, rajin bekerja mencari rezeki, bersilaturahmi, menyambung komunikasi, berkomunikasi dengan baik dan menebar salam, jujur, tidak curang, menepati janji dan amanah, berbuat adil, tolong menolong, saling mengasihi, dan saling menyayangi, sabar dan optimis, bekerja keras dan bekerja apa saja asal halal, kasih sayang dan hormat kepada orangtua serta tidak menipu, pemaaf dan dermawan, berempati, berbela rasa bagian dari manifestasi kebaikan, berkata benar, tidak dusta, selalu bersyukur, tidak sombong dan angkuh, berbudi pekerti 
yang luhur, berbuat baik dalam segala hal, haus mencari ilmu dan berjiwa kuriositas, punya rasa malu dan iman, berlaku hemat, berkata yang baik atau diam, berbuat jujur, tidak korupsi, konsisten atau istiqamah, teguh hati, tidak berputus asa, bertanggung jawab, dan cinta damai. Nilai-nilai karakter dapat diterapkan dalam kehidupan sehari-hari oleh siswa di rumah dan sekolah.

\section{Peran Orang tua dan Guru dalam pembentukan Karakter Islami}

Pembentukan dan pengembangan karakter diawali dari lingkungan keluarga sebagai model utama atau teladan pengembangan karakter anak untuk mewujudkan manusia sebagai makhluk individu, sosial, berakal dan religius (Alwi, 2014). Orang tua atau orang dewasa sekitarnya hendaknya memberikan contoh yang baik pada berbagai aspek perkembangan anak.

Pendidikan dan pengajaran ilmu pengetahuan adalah tugas utama guru, pekerjaan ini hanya dimiliki oleh seorang guru (Getteng, 2014). Tugas guru yang lain antara lain, sebagai model bagi siswanya, mendorong peserta untuk lebih aktif pada kegiatan belajar mengajar, selalu menyampaikan pesan positif, memahami perkembangan anak, mendorong siswa lebih percaya diri serta mandiri sehingga menjadi idola yang baik bagi siswanya.

Peran orang tua dan guru dalam mewujudkan karakter yang Islami memiliki hubungan timbal balik. Keluarga sebagai dasar pembentukan awal sedangkan sekolah sebagai pelengkap pendidikan karakter anak sehingga terwujud siswa sebagai generasi robbani.

\section{METODE PENELITIAN}

Pengumpulan data dilaksanakan pada bulan Juli sampai Agustus 2019. Subyek penelitian ini adalah 5 responden dari PAUD Sekato Desa Mandiangin Kecamatan Minas Kabupaten Siak.
Responden menyampaikan informasi melalui diskusi mendalam namun santai, peneliti mengajukan pertanyaan dengan penuh kekeluargaan pada setiap responden.

Jenis penelitian ini merupakan bagian dari penelitian kualitatif dengan tujuan untuk mendapatkan informasi lengkap tentang kontribusi peran orangtua dan guru dalam pembentukan karakter Islami siswa PAUD Sekato Desa Mandiangin Kecamatan Minas Kabupaten Siak. Hasil penelitian dengan beberapa tahapan, yaitu mengumpulkan data, mereduksi data, menguraikan dan terakhir membuat kesimpulan.

\section{HASIL DAN PEMBAHASAN}

PAUD Sekato Kecamatan Minas Kabupaten Siak adalah terletak pada tengah-tengah Desa Mandiangin, yang berdiri pada tahun 2008 terletak di jalan Utama Dusun Montikato, Desa Mandiangin dengan luas tanah $6500 \mathrm{~m}^{2}$ dengan bangunan seluas $842 \mathrm{~m}^{2}$.

Potensi ruangan yang cukup kecil dengan lahan yang tersedia, ruang bermain sangat kurang dan ruang kelas yang sangat terbatas untuk du akelas (KB dan kelas A) dengan jumlah siswa 38 siswa untuk Tahun Ajaran 2019/2020, diasuh oleh 2 orang guru kelas dan kepala sekolah.

Guru PAUD Sekato selama ini merangkap staf tata usaha, sehingga urusan administrasi PAUD secara keseluruhan ditangani langsung oleh guru. Sementara itu, honorarium guru berasal dari pemerintah daerah Siak yang diterima 2 bulan sekali. Kurikulum PAUD Sekato menerapkan kurikulum yang ditetapkan oleh Dinas Pendidikan.

\section{Kontribusi Peran Orangtua dan Guru dalam Pembentukan Karakter Islami pada Siswa PAUD Sekato}

Penanaman aqidah dan akhlak karimah sejak dini menjadi pondasi masa depan anak. Guru sebagai penyambung 
tangan orangtua selama di sekolah memiliki tanggung jawab juga dalam menumbuhkan kualitas keimanan siswa, karena pembinaan karakter dengan dasar aqidah dan akhlak akan terwujud dalam perilaku siswa sehari-hari dan fasilitator yang tepat dalam pembentukan karakter siswa yang berpedoman pada Pendidikan Islam (La Fua, 2018). Dalam surah Lukman ayat 13 disebutkan:

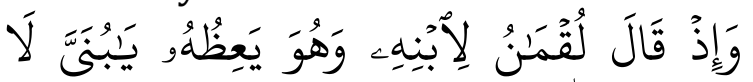

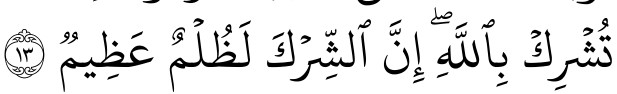
"Dan (ingatlah) ketika Luqman berkata kepada anaknya, di waktu ia memberi pelajaran kepadanya: "Hai anakku, janganlah kamu mempersekutukan Allah". Sesungguhnya mempersekutukan (Allah) adalah benar-benar kezaliman yang besar."

Berdasarkan dalil tersebut menyatakan agar orang tua menjelaskan kepada anaknya mengenai perbuatan syirik atau menduakan Allah SWT merupakan perbuatan dosa besar, karena Allah SWT penguasa tertinggi tidak ada yang mampu menandinginya.

Penanaman nilai-nilai karakter berbasis Al-Qur'an dan Hadits lebih baik dimulai sejak usia dini dengan metode atau pendekatan yang baik berasal dari orang yang paling dekat di sekitarnya, yakni orang tua dan guru sebagai model perilaku hidupnya untuk membentuk jiwa yang berkepribadian Islam serta bertaqwa pada Allah SWT

Paparan yang diungkapkan oleh orang tua A saat wawancara, yakni "Saya senang menyekolahkan anak saya di PAUD Sekato karena banyak perubahannya. Sudah banyak hapalan doa-doa, hapalan surat pendek, tidak malu dan mudah bergaul dengan kawannya. Kami juga sering mengulangulang pelajaran di sekolah agar anak tidak cepat lupa" (wawancara dengan orang tua A, 10 Agustus 2019).

Sementara itu, orang tua C menyatakan "Perubahan anaknya sangat pesat, misalnya masuk rumah selalu mengucakan salam, membaca doa sebelum dan sesudah makan. Pernyataan tersebut disampaikan responden dengan wajah yang ceria seakan-akan ada rasa bangga menyekolahkan anaknya di PAUD Sekato" (wawancara dengan orang tua C, 10 Agustus 2019).

Pernyataan-pernyataan yang telah disampaiakn oleh orang tua tersebut dilengkapi dengan penjelasan oleh kepala sekolah yang penuh semangat bercerita kepada peneliti "Guru-guru selalu memberikan contoh yang baik pada seluruh siswa dimulai dari hal kecil, misalnya bersalaman atau mengucapkan salam walaupun berada di luar lingkungan sekolah. Saya seallu menekankan kepada guru-guru agar selalu terbiasa dengan lingkungan yang Islami karena pendudukan desa Mandiangin ini sebagian besar beragama Islam. Komunikasi dengan orang tua selalu kami usahakan agar kebiasan di sekolah tetap diterapkan di rumah" (wawancara dengan kepala sekolah, 12 Agustus 2019).

Pembiasaan sangat efektif dan efisien diaplikasikan oleh siswa sejak dini di PAUD Sekato, karena anak sangat mudah menirukan apa yang dilihat, didengar dan dialami tanpa dapat memilah segi positif dan negatif.

Sebagaimana yang disampaikan oleh guru PAUD Sekato yang menuturkan bahwa "Pembelajaran agama diajarkan mengenai tauhid, akhlak dan ibadah. Materi Pendidikan agama Islam telah disusun oleh guru kelas dengan menjelaskan secara lengkap dan mudah dimengerti anak, sehingga menjadi bekal anak hingga dewasa kelak" (wawancara dengan guru AA, 12 Agustus 2019).

Generasi saat ini adalah usaha dari generasi sebelumnya sedangkan generasi esok adalah buah hasil dari usaha yang dilakukan saat ini. Cara menyiapkan generasi esok dengan pendidikan yang mengutamakan nilai-nilai aqidah untuk 
terbentuknya akhlak mulia pada setiap anak (Nadlifah, dkk, 2019). Firman Allah SWT dalam surah An-Nisa ayat 9 menyebuthan:

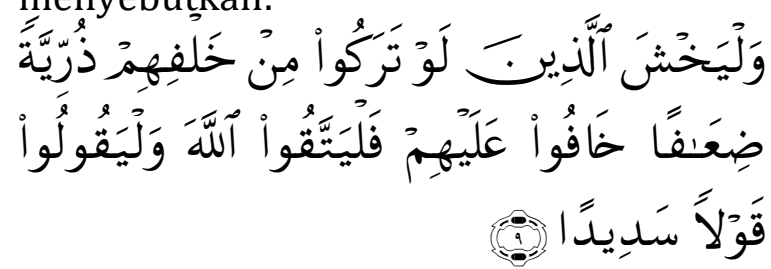

"dan hendaklah takut kepada Allah yakni orang-orang yang seandainya meninggalkan di belakang mereka anakanak yang lemah, yang mereka khawatir terhadap (kesejahteraan) mereka. Oleh karena itu, hendaklah mereka mengucapkan perkataan yang benar".

Pembentukan karakter Islami didasari pada perdamaian, tidak berbuat salah karena Allah SWT melihat tindakan sekecil apapun, bersikap adil, berilmu, saling menghormati, jujur, saling tolong menolong dan menjaga kebersihan (Khan, 2014).

Hasil wawancara terhadap guru menyatakan bahwa besarnya kontribusi peran orang tua dan guru mengajarkan serta menerapkan nilai-nilai karakter yang berlandaskan Islam, memantau perkembangan siswa dan adanya kesepakatan orang tua dan guru agar kebiasaan tersebut selalu dipraktekkan di rumah.

\section{Faktor-faktor yang Mempengaruhi Pembentukan Karakter Islami Siswa PAUD Sekato}

Faktor pendukung pembentukan karakter Islami siswa PAUD Sekato adalah berasal dari orang tua, kedisiplinan, profesionalisme guru dan kepala sekolah, keteladanan, dan pemanfaatan media sosial sebagai alat komunikasi.

Adapun kepala sekolah menjelaskan bahwa "Kebiasaan-kebiasaan yang telah dibimbing dan dilaksanakan di sekolah dengan guru sebagai model utama. Peran orang tua sebagai jembatan terlaksananya pembentukan karakter siswa, sehingga kami sebagai pihak sekolah sangat berharap partisipasi orang tua dalam semua program sekolah serta pembinaan yang telah diterapkan oleh sekolah" (wawancara dengan kepala sekolah, 12 Agustus 2019).

Pendapat yang senada disampaikan oleh orang tua B yang mengungkapkan "Kami sebagai orang tua yang menitipkan anak di PAUD ini selalu bertanya ke anak dan guru kelas tentang pelajaran yang telah dipelajari di sekolah. Selalu itu adanya media sosial, seperti WA sehingga informasi cepat kami terima jika ada infoinfo penting dan kami pun mudah menyampaikan informasi kalau anak tidak masuk sekolah karena anak sakit atau ada acara keluarga" (wawancara dengan orang tua B, 11 Agustus 2019).

Adapun faktor penghambat pembentukan karakter Islami siswa PAUD Sekato adalah kemajuan teknologi, seperti program-program televisi yang tidak sesuai usia anak, penggunaan handphone atau gadget yang tidak dibatasi oleh orangtua, dengan alasan yang penting anak diam dan tidak menggangu pekerjaan orangtua, belum terselenggaranya program parenting di PAUD Sekato, dan lingkungan tempat tinggal siswa yang jauh dari nilai-nilai karakter Islami sehingga dapat mempengaruhi pembinaan karakter yang telah ditanamkan oleh sekolah.

\section{PENUTUP}

Pemaparan hasil penelitian di atas menyimpulkan, yaitu peran orang tua dalam pembentukan karakter Islami siswa PAUD Sekato memiliki kontribusi sebagai penyampung program pendidikan yang telah diajarkan di sekolah dengan mengajarkan menerapkan nilai-nilai karakter yang berlandaskan Islam, memantau perkembangan siswa, dan adanya kesepakatan orang tua dan guru agar kebiasaan tersebut selalu dipraktekkan di 
rumah, sedangkan peran guru juga sangat besar sebagai pendidik dan pengajar di sekolah dengan menyampaikan ilmunya dalam pembentukan karakter Islami di sekolah dan di rumah. Adapun faktor yang mempengaruhi adalah faktor pendukung, yaitu adanya dukungan dari orang tua, kedisiplinan yang diterapkan sekolah, profesionalisme guru dan kepala sekolah, keteladanan guru, dan pemanfaatan media sosial sebagai alat komunikasi. Sedangkan faktor penghambatnya, adalah kemajuan teknologi dengan beredarnya film-film yang isi ceritanya tidak sesuai dengan usia anak, belum terselenggaranya program parenting di PAUD Sekato, ada sebagian siswa dengan lingkungan tempat tinggalnya yang jauh dari nilainilai karakter Islami.[]

\section{DAFTAR RUJUKAN}

Alwi, B. Marjani.. Pendidikan Karakter: Solusi Bijak Menyikapi Perilaku Menyimpang Anak, Makassar: Alauddin University Press, 2014.

Billah, Arif. Pendidikan Karakter Untuk Anak Usia Dini dalam Perspektif Islam dan Implementasinya dalam Materi Sains. Attarbiyah: Journal of Islamic Culture and Education, 1.2 (2016): 243-272.

Getting, Abd. Rahman. Menuju Guru Profesional dan Beretika. Yogyakarta: Graha Guru, 2014.

Ismail, Muhammad Ilyas. Pendidikan Karakter Suatu Pendekatan Nilai. Makassar: Alauddin University Press, 2012.

Kementerian Agama. Al-Qur'an Tajwid dan Terjemah. Jakarta: Darus Sunnah, 2015.

Khan, Sumbul Ansar. Role of Islamic Education in character building of the young generation: A case study from secondary level institutes of Karachi. Educational Research International 3.2 (2014): 97-105.
Kusumandari, Rafika Bayu. Character Education Model for Early Childhood Based on E-Learning and Culture of Java. Indonesian Journal of Early Childhood Education Studies 2.1 (2013): 20-28.

La Fua, Jumarddin, et al. Strategy of Islamic Education in Developing Character Building of Environmental Students in Indonesia. In: IOP Conference Series: Earth and Environmental Science. IOP Publishing, 2018. p. 012149.

Majid, Abdul dan Dian Andayani. Pendidikan Karakter Perspektif Islam. Bandung: PT Remaja Rosdakarya, 2012.

Nadlifah, Suismanto, Hafidh 'Aziz. Pengantar ke Arah Ilmu Pendidikan Islam Anak Usia Dini: Kajian Normatif Ayat dan Hadis Tarbawi tentang Pendidikan Anak. Yogyakarta: Istana Agenc, 2019.

Najib, M., Novan Ardy Wiyani, Sholichin. Manajemen Strategik Pendidikan Karakter Bagi Anak Usia Dini. Yogyakarta: Penerbit Gava Media, 2016.

Prasanti, Ditha, and Dinda Rakhma Fitriani. "Pembentukan Karakter Anak Usia Dini: Keluarga, Sekolah, Dan Komunitas? (Studi Kualitatif tentang Pembentukan Karakter Anak Usia Dini Melalui Keluarga, Sekolah, dan Komunitas)." Jurnal Obsesi: Jurnal Pendidikan Anak Usia Dini 2.1 (2018): 13-19.

Salim, Moh. Haitami. Pendidikan Agama Dalam Keluarga: Revitalisasi Peran Keluarga dalam Membangun Generasi Bangsa yang Berkarakter. Jogjakarta: Ar-Ruzz Media, 2013.

Satriani, Andi. Pembentukan Karakter Islami Peserta Didik di SD Islam Terpadu Wahdah Islamiyah 01 Kota Makasar. Skripsi. Universitas Islam Negeri Alauddin Makasar: Fakultas Tarbiyah dan Keguruan, 2017. 
Sriwahyuni, Ery. Pembentukan Karakter Islami pada Anak Putus Sekolah (Studi Kasus di Pondok Pesantren API Darussalam Pulungsari Kecamatan Kaliwiro Kabupaten Wonosobo. Skripsi. Universitas Negeri Semarang: Fakultas Ilmu Sosial, 2015.

Ulya, Machya Afiya. Penanaman Karakter Islami melalui Program Hafalan Takhasus di SD $\mathrm{Hj}$. Isriati Baiturrahman 2 Semarang Tahun ajaran 2015/2016. Skripsi. Universitas Islam Negeri Walosongo Semarang: Fakultas Ilmu Tarbiyah dan Keguruan, 2015.

Wahyuni, Ida Windi. "Penerapan NilaiNilai Moral pada Santri TPQ AlKhumaier Pekanbaru." Generasi Emas: Jurnal Pendidikan Islam Anak Usia Dini 1.1 (2018): 51-61.

Zaedi, Muhamad, and Redha Dwi Rizkia. "Analisis Model Pembelajaran Berkarakter dan Relevansinya Terhadap Pendidikan Islam (Studi Analisis Manajemen Pendidikan Karakter Perspektif E. Mulyasa)." Risâlah, Jurnal Pendidikan dan Studi Islam 5.2 (2019): 20-39. 